\title{
The Application of Foreignization and Domestication in the Translation
}

\author{
Lijun Yang \\ School of Business and Trade \\ Huanghe Science and Technology College \\ Zhengzhou, China \\ e-mail: 379630960@qq.com
}

\begin{abstract}
The translation is a trans-cultural exchange, a good communication has become a bridge among different countries day by day along with the frequent intercourse of various countries and various nationalities, and good translation can promote the exchange. The foreignization and the domestication have become the focal points which the people argued in the recent years. It is very difficult for the translation to maintain the style and the flavor of the original work as far as possible and to be understood and accepted by the readers. Therefore some people think the foreignization may be better, but simultaneously other people thought that the domestication is more appropriate. But in fact the excessive domestication and foreignization are not the best methods of translation, if you wish to make your work of translation both conform to the original text and be faithful to the original text, simultaneously the readers will understand and accept your translation, the foreignization and the domestication should be unified, the relation between them is supplementary and may not be substituted by each other. Only unifying them, the effect of the translation will be much better.
\end{abstract}

Keywords - translation; foreignization; domestication

\section{INTRODUCTION}

The language is not only a mark but also an important component of cultural structures to carry massive information of culture. So the exchange of two languages is the exchange of two different cultures. The exchange must draw support from translation by no means a direct communication between two languages; obviously it is the essence of translation to realize the communication between different cultures. However each nationality has its own unique culture, which has caused the phenomenon of cultural conflict in translation of language. The difficulty of translation lies in not only the difference of the language but also the understanding and the translation of cultural elements. But with regard to cultural processing there are two different opinions, namely domestication and foreignization, and they are debated unceasingly over a long period of time. It is a biased view for us to make a conclusion of which one is better, they are both important. The relations between "the domestication and the foreignization" should be antagonistic and unified and can not be substituted by another. But in some period, as a result of social and cultural environment, as well as the different understanding of people to the essence of translation, some kind of strategy resided in the dominant position. Owing to the critic and the publisher often paid great attention to the readability of the work of translation, the common readers also liked the common and simple translation, and moreover this tendency also was in accordance with the development trend of translation research, the domestication had been always in the dominant position in our country. But until today the economic globalization and information networking as well as business intercourse and cultural exchange have unceasingly been strengthened, hence the demand of people for understanding foreign cultures are getting stronger and stronger also. The entire above mentioned all request translators introduce and disseminate the foreign culture to a much greater extent, which has created an advantageous environment for the strategy of foreignization. But advocating foreignization does not equal to neglect or even repel the domestication; both of them have the irreplaceable and supplementary function.

\section{ARGUMENTS OF DOMESTICATION AND FOREIGNIZATION}

The argument of domestication and foreignization has begun for a very long time, the scholars of China and the West also hold the personal opinion respectively.

\section{A. China's Argument}

In the ancient times, the argument of domestication and foreignization comes from the argument of article and nature in literature translation of Buddhist. Until the modern times, the "nature" and the "article" had been substituted by the "literal translation" and "free translation". In the period of Movement of New Culture, Lu Xun and Qu Qiubai advocated the literal translation; they believed that the translation must own the exotic sentiment. But there are some scholars who advocated free translation, Guo Moruo was one of them, they thought that the literal translation harmed the refined language, although the meaning of the words might be lost when free translation, the charm of the original could be caught. Contemporary China's argument of domestication and foreignization may be regarded as extending and sublimates of the argument of literal translation and free translation in last century $20 \sim 30$ s.

\section{B. Western Argument}

In the West, the domestication and the foreignization could be traced back to word for word translation and sense for sense translation which were said by Cicero, Horace, St. Jerome etc. 
in ancient Rome times. In the 1970s, at the forum of contemporary international translation, Venuti is the representative of foreignization. He proposed the concept of "foreign and counter translation". This kind of translation desirably gave prominence to the "foreignness" of the original in target language, style and other aspects. In this concept he proposed one strategy of opposing smooth and easy translation, the translator did not compromise to the reader, requested the reader to accept the foreign culture and the special place. Nida was the representative of domestication. He proposed the concept of the "closest natural equivalence". The dynamic goal of equivalence which was the expression of translation should be the complete nature; the primitive pattern of behavior of the source language should be integrated as far as possible into the translation readers' culture.

\section{FOREIGNIZATION AND DOMESTICATION IN THE PRACTICE OF TRANSLATION}

The domestication and the foreignization are two kinds of completely contradictive manners of translation. The traditional principle of translation is the "smooth translation", namely "domestication", the translation can be read and understood easily, the crabbed incoherent phenomenon does not exist, and it is just like the original. In UK-US translation culture, the theory of smooth translation's domestication has occupied the dominant position; the translator should take the response of readers as the center. Some people proposed to publish the different translation in view of the different type's reader. American scholar, through the study of Western translation history Lawrence Venuti raised questions about the domestication, and criticized the former tendency of aiming at target language which has occupied the dominant position. He advocated the translation of foreignization. This kind of translation retained the foreignness of the foreign text, and its goal was to develop one kind of translation theory and practice thus it resisted taking the cultural values of target language as the dominant position. In the translation of cross languages, how to make process of words and expressions which contain the strong cultural individuality and the form of expression is far from the primitive language? As a pair of contradictory concept, when dealing with the cultural characteristic original text, the translator should adopt actually the foreignization or the domestication and balance both sides.

\section{A. Foreignization}

The smooth translation played an irreplaceable role in disseminating the foreign culture in our culture. Because the cultural communication among various countries is frequent day by day, our country's culture has taken the tolerant manner more and more to the foreign culture, the foreignization translation also slowly is accepted by the reader. From the domestication to the foreignization, what the strategy is adopted is decided finally by the translation's goal and reader's object as well as the language environment. It will not very unbeneficial for increasing use of "foreignization" translation moderately to enrich the language, to disseminate the native place's culture and accept the external culture.
There are obvious cultural characteristic factors when making the process of the original text, its translation's result inevitably brings some new manifestation and appendix cultural connotation which are different from mother tongues. In fact as the cultural important carrier, language is seldom "self-sufficient" and seldom isolates with the external factors. On the contrary the language is an open system, which has formidable ability of containing and absorption. The foreignizating translation played a more vital role in this process of day by day deepening communication between various countries and enriching languages. Such as Chinese “洗手间” (wash hands), “鳄鱼的眼泪” (crocodile tears), “因 特网” (internet); English “taiji quan” (Chinese 太极拳), “typhoon”(Chinese 台风). These glossaries do not exist originally in Chinese and English language, through the foreignizating translation the translators make almost every one accept the words and expressions with foreign cultural character gradually, and they can widely disseminate and utilize in the mass culture. The language is not a sealed system, good foreignizating translation is advantageous to absorb some kind of the new elements of foreign language, once they are accepted by the society, namely an agreement has become a practice, and they have joined to the traditional language culture and become new members. The result inevitably will enrich the way of expression, promote language to be close to and exchange each other as well as enhance vitality of language.

Because of wide exchanges among international politics, economy, and culture, the difference between various countries has been reduced gradually, the "global village" and "globalization" are becoming the tendency of the world's development, and the people need to be familiar with the outside world. Under the great background of cultural fusion, the foreignizating translation may be much beneficial to not only introduce the history of our country to the foreign country, but also make the readers of our country have the opportunity to be familiar with foreign character and style, and then the goal of Trans-Cultural communication can be achieved.

Peter Newmark called foreignizating translation as the semantic translation. In the translation the foreignization is used, the cultural information of the original language will obtain the greatest degree of retention, and the readers will feel more atmosphere of the original language culture. However, it should be clear that the foreignization is not simple translation from word to word; such translation from word to word does not be regarded as the true translation. When making translation, we often receive influences of many factors, and the translation's goal is the key factor in so many factors. For example the translation of The Dream of the Red Chamber is a typical foreignization. It is a classic work and cultural treasure, which might also be called as the Chinese cultural encyclopedia. Therefore translation of this book is not only simple from Chinese words to English words, it is more important to introduce Chinese broad and profound culture to the West's readers, not only the original flavor must be reserved but also the essence should be showed to the West's reader, in 
addition the translation must be understood easily by Western readers. From above we can see we must know very well the target language's custom, cultural information and cultural difference, so this book chose the method of foreignization because both of them know well the basic skills and knowledge of Chinese and English. It will be better to retain the analogy of English phrase, the image, national and local color in the translation without violating language standard of the translation as well as causing the wrong association. The cultural element is playing a noticeable role. Regardless of using any method, the cultural element must be considered. If there is something wrong with the culture and the understanding, the translation will come out fault inevitably. For example: American writer Pearl S. Buck's translation of All Men Are Brothers, the mistake had come out because of the cultural misunderstanding of the translator, there was a Chinese phrase: “三四个笁酒的酒保都手忙脚乱，搬东搬西” in the 9th chapter of All Men Are Brothers. Her translation was: But these serving men were so busy, their hands and feet were all confusion, and they were moving things hither and thither, east and west. Here Chinese “搬东搬西” was misunderstood by her as moving the things to the east or west, namely "the direction", in fact they all refer to the things. She only translated them from the Chinese words to English words simply, the meaning and the charm of the original text was nothing left.

\section{B. Domestication}

The translation of domestication theoretically regards the language as the tool of communication, easy understanding is emphasized and equivocal or the different meanings are avoided in the practice. Generally speaking, there will be difficult understanding situation because of the cultural difference between the original text and the translation, the culture of translation had better take replace of the primitive culture, namely there is not the equivalent foreign words and expressions in the language, the similar expressions should be used, which turned them into the familiar translation culture of the reader. For many years the translation of domestication had been adopted frequently in the translation because they used almost the same frequency of the source language's words and expressions and certain words and expressions of target language to translate the original language, it can make the translation read quite typically and vividly. The cultural difference of different language requests the translator to maintain high cultural consciousness in the process of translation, because generally those words which contain rich cultural connotations can not be reappeared in the translation easily. Such as Chinese idiom “引狼入室”, it has reflected Chinese hold the special or unique psychological feeling to the wolves, it is rooted in the Chinese national culture. But English nationality hold different psychological experience and cultural connotation to the wolf from Chinese, they even believe the wolf is brave. Therefore if we translate them into "to guide the wolf into the room", the English readers will be unintelligible. We had better translate them into "to set a fox to keep one's geese", the fox and geese are familiar with the English readers, so it will be understood well. Therefore the translation of domestication can relax cultural contradictory of language and play the positive role truly in substituting the cultural difference of different language cultures. But to overemphasize the smooth domestication also will bring some flaws: first, the meaning of the original text will be lost; second, the original text's semantics may be cut-off.

American scholar Venuti ever made the description of domestication, he said that the domestication should observe current mainstream values of the target language's culture and use the conservative method of domestication, thus conform to the native place's standard, publication fashion and political object. It is the most major characteristic of domestication to use the smooth and pure target language to translate the original. When the translator adopts the kind of method, the smooth translation covered the difference of different cultures, the target language's mainstream values of culture has substituted for cultural values of the source language, the original text loses the strange feeling, then the reader will rapidly accept the translation without any barrier. The domestication starts from the cultures of target language and takes the translation readers as the center, as well as stresses the vivid and pure translation, thus the original text's culture and language style are changed to the local cultures and languages. Such as many idioms and phrases in Chinese could not find the corresponding way of expression in English, if we translate them with the method of domestication, they will be understood easily. For example: To spend money like water (Chinese “挥金如土”); To laugh off one's head (Chinese “笑 掉大牙”). Translators have utilized the method of domestication to make the translation ingeniously and they be appreciated successfully by the Chinese readers. Just the foreignization can not be applied into all such above situations, but domestication will lose the original meaning.

\section{Suitable Supplementary of Foreignization and Domestication}

Indeed the degree of "domestication" and "foreignization" is the question which each translator need ponder earnestly. Pursuing constantly and excessively domestication can cancel many characteristics of styles, art, cultures and so on, and does not benefit the reflection of original work's spirit and cultures; the goal of understanding the outside world can not be obtained as well. Similarly foreignization in translation often causes the translation to be obscure and become the cultural exchange's barrier, it is very difficult for the readers of target language to understand and accept the translation. So it is very necessary to make well process of dialectical relations between the domestication and the foreignization, to properly unify them and achieve the best translation. The utilization of them should be moderate and appropriate; According to different text and the different readers, sometimes one of them or both of them should be adopted, For example: Shen Fu's Six Chapters of a Floating Life was an autobiography of the author; it narrated the happy marriage life which the author yearned for. The scenery description, the literature and the art's criticism were inserted into the whole book, which can be regarded as essence of our country's traditional language culture. Through comparing the same original text and the translation, we can find the different strategies of translation are adopted by Chinese and the Western translator. In the 
original Chinese text there are such a few words “南行十里即 泰兴县城”. Chinese Lin Yutang translated it into "I was to go straight south for ten li until I should reach Taixing City", but western Black translated it into "Go south about three miles". Their language of translation has the common place. Although the language's form is very different, it is still possible to express the same content. The translator's choice of words and expressions usually may reflect his translation's strategy. But when the translator has the multiple options, the orientation of his translation's strategy will be more obvious. From the above example, we can see Lin Yutang utilized the domestication, but foreign Black used foreignization. Lin Yutang retained its exotic atmosphere with the aid of transliteration, Black transformed China's unit of length into Britain's Unit of length, finally the original national characteristics are eliminated. But different readers will have different understanding; it will be difficult for the western readers to understand the "ten li". If he wants to understand more China's cultures, the Lin Yutang's translation is good, but if he only wants to read the story, the Black's translation is better. So the reading goal of the readers decides whether the translation is good or not to some extent. Since the domestication and the foreignization can not solve all problems alone in translation, therefore in the actual translation we should unify ingeniously them according to the special details and factors. Through the massive practices and summarize, we may also discover some skills. For instance when the cultural difference of the original language and the target language is not very great and literal translation can express the original text's meaning, the writing understanding can not be affected as well, then foreignization should be chosen. But if the cultural difference is too big to express the original meaning through literal translation and the foreignization, or even it may become the barrier of the understanding fully, then the translator must adopt the domestication. Therefore, whether the domestication or the foreignization should be adopted, we should consider many factors to make the choice, such as translator's cultural education, the translation's goal, the target language's custom, reader's response, the original language's characteristics as well as acceptable ability and so on. It's better for translation to use both of them than use the single of them, and the translation will be more flexible. For instance Chinese “金子 终得金子换”, some people has translated it into “True gold will find it price." It not only retains the cultural image of original language but also displays the goal language's characteristic, namely it transmits the original text's information faithfully and conforms to the translation reader's custom.
Besides the above, another thing is also very important, that is basic skill of translator's language. The translator need own the ability of good grasping native language and control the target language and understand cultural information which the target language contains.

\section{CONCLUSION}

In summary, we can understand the argument of the foreignization and the domestication has puzzled many translators for a long time. The foreignization and the domestication also may coexist forever, the successful translation neither leaves the foreignization, nor does the domestication. The translator should make the choice according to many kinds of factors and alternately use a proper one. We may see from the above examples, they are contradict each other, but in essence they are supplementary. The excessive domestication and the foreignization are not the best translation's methods, if we want to make the work of translation both conform to the original text and be faithful to the original text, simultaneously the readers can understand and accept them easily, so they should be unified. Under the background of opening and exchange, the people have realized it is very important to remain the individual and unique culture, thus the individual and unique culture are tolerant more. We make correctly process of their unified and antagonistic relations, there will be a good effect.

\section{ACKNOWLEDGMENT}

I would like to give my heartfelt thanks to many people for their help in my academic studies over the past years. My deepest gratitude to my family, thanks for their kindness, patience, encouragement. Thanks to my school that has give me this delicious opportunity. And thanks to my dear friends who have given their great help to me in my research.

\section{REFERENCES}

[1] Baker, Mona1 Routledge Encyclopedia of Translation Studies[M]London and New York: Routledge, 1998.

[2] Shuttleworth, Mark \& Moira, Cowie. Dictionary of Translation Studies[Z]. Shanghai: Shanghai Foreign Language Education Press, 2004

[3] Wilss, Wolfram. The science of translation: problems and methods[M] ShangHai: Press of ShangHai English Education, 2001.

[4] Newmark, Peter. Approaches to Translation [M]. Shanghai: Shanghai Foreign Language Education Press, 2001.

[5] Nida, Eugene A. Language, Culture and Translating [M]. Shanghai: Shanghai Foreign Language Education Press, 1993. 